\title{
MODELAGEM MATEMÁTICA PARA DESCRIÇÃO DA CINÉTICA DE SECAGEM DA MISTURA DE BAGAÇO DE MALTE E LEVEDURA (Saccharomyces cerevisiae)
}

\author{
E.V. BOFFO ${ }^{1}$, G.M.C. da SILVA ${ }^{1}$, R. KLAGENBOECH ${ }^{1}$, J.J. TONEL ${ }^{2}$ \\ ${ }^{1}$ Universidade Tecnológica Federal do Paraná, Coordenação do Curso de Tecnologia em \\ Processos Químicos \\ ${ }^{2}$ Universidade Estadual do Oeste do Paraná, Departamento de Engenharia Química \\ E-mail para contato: gmarina@utfpr.edu.br
}

\begin{abstract}
RESUMO - Durante o processo industrial de produção da cerveja ocorre a geração de subprodutos, dentre eles o bagaço de malte e o excesso de leveduras (Saccharomyces cerevisiae). Assim, este trabalho objetivou-se estudar a cinética de secagem da mistura bagaço/levedura, e analisar os ajustes dos dados experimentais com os modelos de Henderson e Pabis, Newton e Lewis, Midilli e Page. Utilizou-se a proporção de $80 \%$ de bagaço de malte e $20 \%$ de levedura. A secagem foi realizada em um secador de túnel de vento na temperatura fixa de 70 ${ }^{\circ} \mathrm{C}$ e com as velocidades de fluxo de ar de 1,0,1,2,1,4,1,5 e 2,0 m s${ }^{-1}$. Através das curvas de secagem, observou-se a presença do período inicial e do período decrescente. Verificou-se, também, que quanto maior a velocidade do ar de secagem, menor é o tempo de secagem e menor é a umidade final do produto. A desidratação com velocidades maiores apresentaram, ainda, maiores taxas de secagem. O modelo semi-empírico de Midilli foi o que apresentou os melhores resultados para a secagem da mistura bagaço de malte e levedura, com coeficientes de determinação acima de 99,98\% para todas as condições estudadas. No entanto, o modelo de Page apresentou bastante relevância aos ajustes aplicados nos diferentes fluxos gasosos, obtendo-se um coeficiente de determinação próximo a 99,95\%.
\end{abstract}

\section{INTRODUÇÃO}

Os resíduos gerados nos processos agroindustriais representam perdas econômicas no processo produtivo e se não receberem destinação adequada podem proporcionar problemas ambientais devido a sua carga poluidora (BROCHIER, 2007). Dentre estes resíduos salientase o resíduo úmido de cervejaria, o qual constitui-se de bagaço de malte e do excesso de leveduras (Saccharomyces cerevisiae). O bagaço de malte é obtido na etapa de preparação do mosto e o excesso de leveduras é originado no processo de fermentação.

A mistura destes resíduos apresenta elevado teor de umidade, o que torna o material propício para o crescimento de micro-organismos indesejáveis, além de prejudicar o transporte devido ao grande volume. Uma das formas de minimizar estes efeitos seria com a utilização da operação de secagem. A secagem tem por objetivo reduzir a umidade para a conservação do material, o armazenamento por um longo período de tempo e a redução dos custos de transporte (JESUS, 2002). 
Para avaliar as melhores condições de secagem da mistura bagaço/levedura faz-se necessário o estudo da cinética do processo, observando as condições de temperatura, umidade e velocidade do ar. A literatura cita vários modelos matemáticos para analisar a desidratação de produtos higroscópicos, sendo os mesmos ferramentas úteis na estimativa do tempo necessário para diminuição do teor de umidade, sob diferentes condições de secagem, auxiliando nas tomadas de decisão e contribuindo na melhoria da eficiência do processo (ANDRADE, BORÉM e HARDOIM, 2003). Os modelos utilizados para descrever o movimento da água durante a secagem de produtos alimentícios são os empíricos, os semi-empíricos e os difusivos baseados na lei de difusão de Fick (PINEDO, 2003).

Neste contexto, o presente trabalho tem por objetivo estudar o comportamento cinético na secagem da mistura bagaço de malte e levedura (Saccharomyces cerevisiae) e analisar os ajustes dos dados experimentais com diferentes modelos matemáticos obtidos na literatura.

\section{MATERIAIS E MÉTODOS}

As matérias-primas utilizadas para este estudo foram a levedura do gênero Saccharomyces cerevisiae e o bagaço de malte, ambos cedidos por uma indústria cervejeira da região Oeste do Paraná - Brasil. As amostras foram acondicionadas em embalagens plásticas a $-18{ }^{\circ} \mathrm{C} \pm 2{ }^{\circ} \mathrm{C}$. $\mathrm{O}$ descongelamento do bagaço ocorreu durante 24 horas e o da levedura por 4 horas em temperatura ambiente (MENEZES, 2010).

Após o descongelamento, a levedura passou por uma etapa de centrifugação para descarte de sua forma líquida. Feito isso, as amostras foram submetidas ao processo de homogeneização, considerando a proporção de $80 \%$ de bagaço de malte e $20 \%$ de levedura.

$\mathrm{O}$ estudo da secagem convectiva da mistura bagaço/levedura foi executado através do levantamento dos dados cinéticos obtidos de um secador convectivo de túnel de vento, da marca Eco Engenharia Educacional, conforme mostrado da Figura 1.

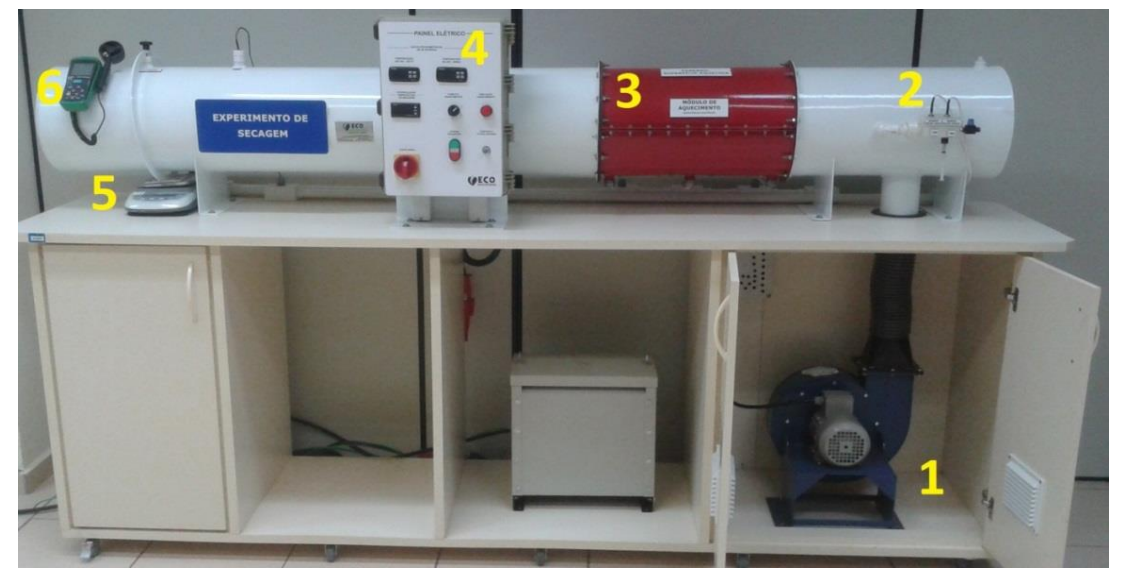

Figura 1 - Módulo experimental de secagem para determinação das curvas de secagem da mistura bagaço/levedura.

O módulo é constituído por um soprador de ar (1); psicrômetro (2); sistema de aquecimento (3); painel de controle (4); sistema de pesagem (5), composto por uma balança semi-analítica; e um anemômetro (6) para medir a velocidade do ar na saída. O módulo, também, apresenta uma câmara de secagem, na qual é acoplada uma bandeja de inox, com área de $0,01766 \mathrm{~m}^{2}$ e $1,0 \mathrm{~mm}$ de espessura, que foi utilizada como suporte para aproximadamente $160 \mathrm{~g}$ de amostra. 
Os ensaios de secagem foram realizados na temperatura fixa de $70{ }^{\circ} \mathrm{C}$ e com velocidade de fluxo gasoso de 1,0,1,2, 1,4, 1,5 e 2,0 m.s ${ }^{-1}$. Durante o processo de secagem, as massas das amostras foram determinadas nos seguintes intervalos de tempo: nos primeiros 30 minutos, intervalo de 2 minutos; até 1 hora, intervalo de 5 minutos; de uma hora à uma hora e meia, intervalo de 10 minutos; até massa constante, intervalo de 15 minutos (MENEZES, 2010).

A partir dos dados experimentais foram determinadas as curvas de secagem e as curvas de taxa de secagem, sendo as primeiras expressas por gráficos de umidade em base seca $\left(\mathrm{X}_{\mathrm{bs}}\right)$ em função do tempo, e as últimas expressas pela derivação de suas respectivas curvas de secagem em função de umidade. A umidade do produto em base seca e a taxa de secagem são representadas pelas Equações 1 e 2, respectivamente.

$$
\begin{aligned}
& X b s=\left(M_{(t)}-M_{\text {seca }}\right) / M_{\text {seca }} \\
& R=d X / d t=\left(-M_{\text {seca }} / A\right) .\left(d X_{b s} / d t\right)
\end{aligned}
$$

Onde: $X b s$ é a umidade do produto na base seca (g de $\mathrm{H}_{2} \mathrm{O} / \mathrm{g}$ de sólido seco) a cada instante; $M_{(t)}$ é a massa do produto (g) a cada intervalo; $M_{\text {seca }}$ é a massa seca do produto $(\mathrm{g})$ obtida em estufa a $105^{\circ} \mathrm{C}$ por 24 horas; $R$ ou $d X / d t$ é a velocidade ou taxa de secagem ( $\mathrm{g}$ de $\mathrm{H}_{2} \mathrm{O} / \mathrm{m}^{2} \mathrm{~s}$ ); e $A$ é a área de superfície exposta a secagem $\left(\mathrm{m}^{2}\right)$ (MENEZES, 2010).

As curvas de secagem foram ajustadas aos modelos matemáticos representados na Tabela 1, os quais apresentam grande relevância ao estudo da secagem de produtos agrícolas.

Tabela 1 - Modelos matemáticos de regressão não-linear, avaliados para predizer a secagem da mistura bagaço/levedura

\begin{tabular}{|l|l|l|}
\hline Modelo & Equação & Referência \\
\hline Henderson e Pabis & $R U=a \cdot \exp (-k \cdot t)$ & Henderson e Pabis (1961) \\
\hline Midilli et al. & $R U=a \cdot \exp \left(-k \cdot t^{n}\right)+b . t$ & Midilli et al. $(2002)$ \\
\hline Newton e Lewis & $R U=\exp (-k \cdot t)$ & O'Callaghan et al. (1971) \\
\hline Page & $R U=\exp \left(-k \cdot t^{n}\right)$ & Bruce (1985) \\
\hline
\end{tabular}

Em que: $R U$ é a razão de umidade do produto (adimensional); $k$ é o coeficiente de secagem $\left(\mathrm{s}^{-1}\right) ; a, b$ e $n$ são as constantes dos modelos; e $t$ é o tempo de secagem (s) (Martinazzo et al., 2007).

A fórmula da razão de umidade (RU) experimental está representada pela Equação (3).

$$
R U=\left(X-X_{e}\right) /\left(X_{o}-X_{e}\right)
$$

Onde: $X$ é a umidade em base seca (\%); $X_{e}$ é a umidade de equilíbrio em base seca (\%); e $X_{o}$ é a umidade inicial do produto em base seca $(\%)$.

\section{RESULTADOS E DISCUSSÃO}

Com os dados obtidos experimentalmente para a secagem da mistura de bagaço de malte $(80 \%)$ e levedura $(20 \%)$ foram construídas as curvas de secagem e taxa de secagem para a temperatura fixa de $70{ }^{\circ} \mathrm{C}$ e nas variações do fluxo gasoso de $1,0,1,2,1,4,1,5$ e 2,0 m 
$\mathrm{s}^{-1}$. Os experimentos foram realizados em duplicata e durante os mesmos, a temperatura ambiente manteve-se $26 \pm 2{ }^{\circ} \mathrm{C}$.

A Figura 2 (a) expressa a redução da umidade da mistura em relação ao tempo para cada condição de secagem. A umidade em cada instante foi calculada através da Equação 1. A partir da derivação das respectivas curvas de secagem em função de umidade foram obtidas as curvas de taxas de secagem através da Equação 2. As curvas da taxa de secagem, para as diferentes condições de secagem estão representadas pela Figura 2 (b).

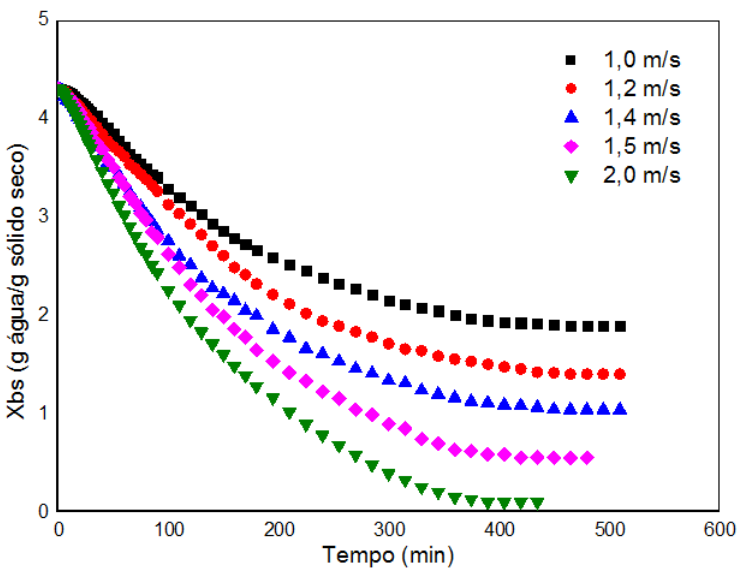

(a)

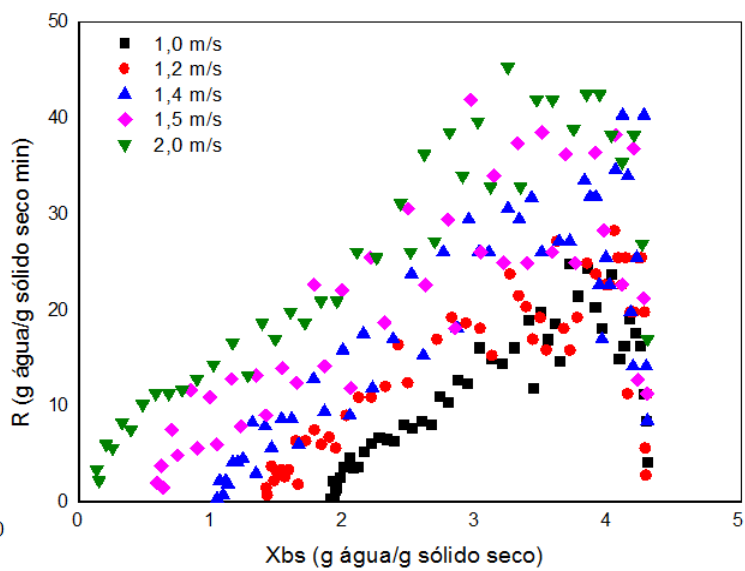

(b)

Figura 2 - (a) Curvas de secagem para a mistura bagaço/levedura (80\%/20\%), na temperatura de $70^{\circ} \mathrm{C}$ e com velocidades de $1,0,1,2,1,4,1,5$ e $2,0 \mathrm{~m} \mathrm{~s}^{-1}$. (b) Curvas da taxa de secagem nas mesmas condições.

Com base na Figura 2 (a), observa-se que há uma grande influência da velocidade do ar quanto ao tempo de secagem da mistura, já que os fluxos gasosos de 1,0, 1,5 e 2,0 m s${ }^{-1}$, por exemplo, atingiram o ponto de umidade de equilíbrio em 480, 420 e 390 minutos, respectivamente. Ou seja, quanto maior a velocidade, menor o tempo de secagem. Outro fato observado foi que quanto maior o fluxo gasoso, menor é a umidade final do produto, pois ao final da secagem com fluxo gasoso de $1,0 \mathrm{~m} \mathrm{~s}^{-1}$, a amostra obteve 45,37\% de sua massa total desidratada (umidade perdida), enquanto que para as velocidades de 1,2, 1,4, 1,5 e 2,0 m s foram de 54,70,61,55, 70,75 e 79,25\%, respectivamente.

Azoubel, Barbosa Jr. e Murr (2003) estudaram a cinética de secagem de tomate cereja nas temperaturas de 50 e $70{ }^{\circ} \mathrm{C}$, com as velocidades do ar de 0,75 e $2,60 \mathrm{~m} \mathrm{~s}^{-1}$. Os autores verificaram que os aumentos da temperatura e do fluxo gasoso na secagem favorecem a remoção de umidade dos frutos, tornando a curva de secagem mais acentuada, o que implica na redução do tempo de processo.

Pela análise dos dados experimentais da Figura 2 (b) verifica-se que o processo de secagem da mistura de bagaço de malte e levedura apresenta dois períodos distintos de secagem baseados no comportamento da velocidade de secagem. Inicialmente tem-se um período inicial e logo em seguida um período de taxa decrescente, ou seja, nota-se que não há a presença do período de taxa constante. Foust et al. (1982) relataram que em sólidos nos quais a difusão controla o movimento do líquido, estes tendem a ter períodos com taxas constantes mais curtos, ou mesmo sem que haja um período de taxa constante perceptível.

O período inicial caracteriza-se pela condição de equilíbrio entre as temperaturas da 
amostra e do meio secante, assim, observando-se a Figura 2 (b), salienta-se que a amostra estava com uma temperatura menor que a do meio secante. Ao igualarem esta temperatura, deu-se início ao período de taxa decrescente. O período de taxa decrescente apresentou uma predominância maior para a secagem do material em estudo, em vista disso, a maior parte do tempo gasto para a secagem foi para a retirada de umidade interna presente na amostra.

Outros autores também já observaram a ausência do período de taxa constante, podendo citar o trabalho de Gouveia (1999) que avaliou a cinética de secagem de gengibre (Zingiber officinalle, Roscoe) em um secador de leito fixo, utilizando temperaturas de 50, 60, 70 e $80{ }^{\circ} \mathrm{C}$ e velocidades do ar de secagem de 1,0 e $1,5 \mathrm{~m} \mathrm{~s}^{-1}$. Segundo a autora, a cinética de secagem ocorreu no período de taxa decrescente, sendo fortemente influenciada pela temperatura em relação à velocidade do fluxo gasoso do processo.

Os dados obtidos experimentalmente evidenciaram a influência do fluxo gasoso no processo de secagem da mistura bagaço/levedura, visto que a desidratação com velocidades maiores obtiveram maiores taxas de secagem, além de alcançarem menores umidades de equilíbrio.

Os ajustes matemáticos dos dados experimentais de secagem foram realizados de acordo com os modelos de Henderson e Pabis, Newton e Lewis, Midilli et al. e Page. Realizou-se a análise de regressão não linear pelo método de estimação Quase-Newton, empregando-se o programa computacional Statistica versão 8.0.

A Figura 3 representa os ajustes dos dados experimentais de secagem da mistura bagaço/levedura na temperatura de $70^{\circ} \mathrm{C}$ e nas velocidades de $1,0,1,2,1,4,1,5$ e 2,0 $\mathrm{m} \mathrm{s}^{-1}$.

Os valores do coeficiente de determinação $\left(\mathrm{R}^{2}\right)$ e os parâmetros "k", "n", "a" e "b" dos modelos utilizados para a secagem da mistura bagaço/levedura $(80 \% / 20 \%)$ na temperatura de $70{ }^{\circ} \mathrm{C}$ e nas velocidades de $1,0,1,2,1,4,1,5$ e $2,0 \mathrm{~m} \mathrm{~s}^{-1}$ estão representados na Tabela 2.
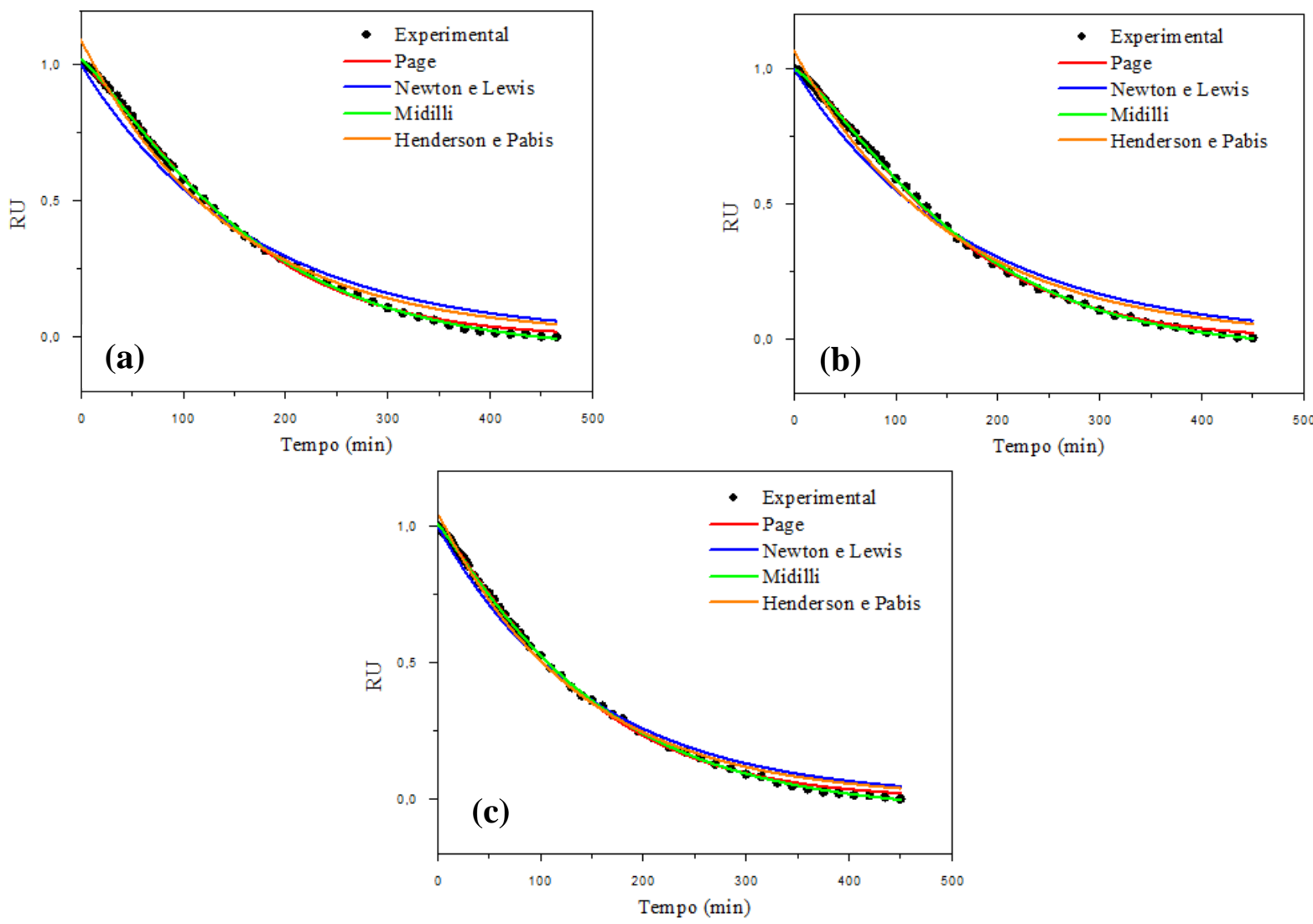

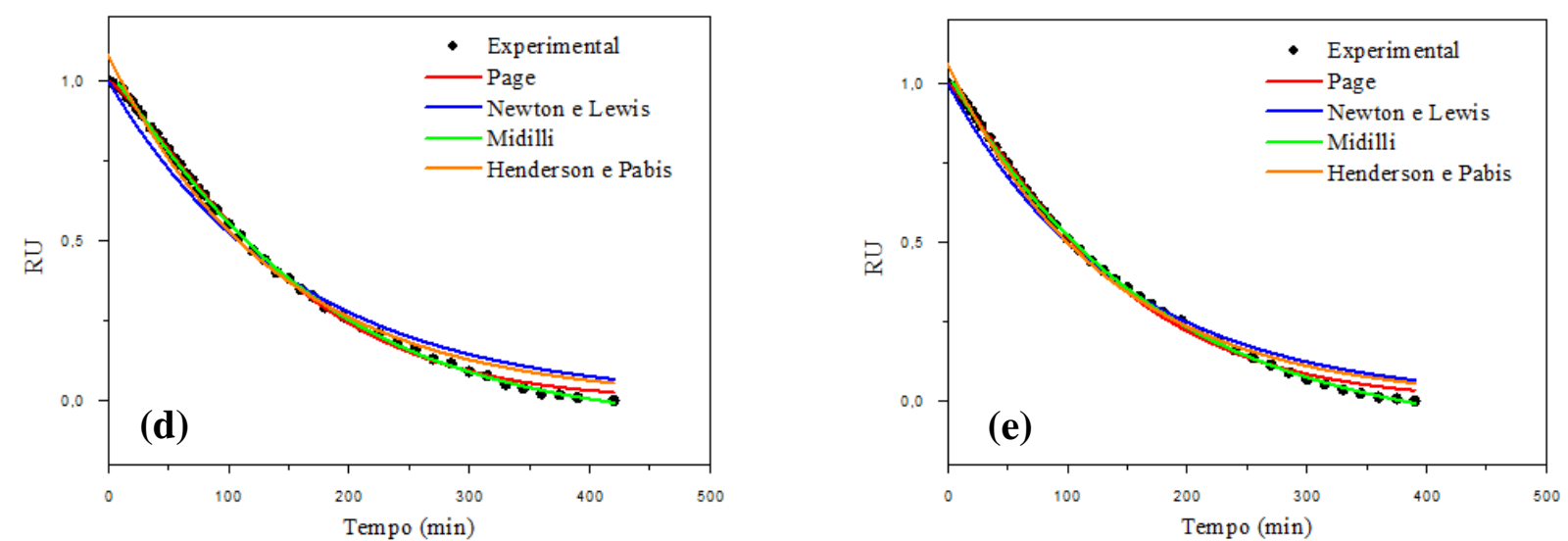

Figura 3 - Ajustes dos modelos matemáticos para as secagens da mistura bagaço/levedura na temperatura de $70{ }^{\circ} \mathrm{C}$ e com as velocidades de 1,0 (a), 1,2 (b), 1,4 (c), 1,5 (d) e 2,0 $\mathrm{m} \mathrm{s}^{-1}$ (e).

Tabela 2 - Coeficientes de determinação e parâmetros "k", "n", "a" e "b" para os modelos analisados, durante a secagem da mistura bagaço/levedura nas diversas condições estudadas

\begin{tabular}{|c|c|c|c|c|c|c|}
\hline Modelos & $\begin{array}{l}\text { Velocidade do ar } \\
\qquad\left(\mathrm{m} \mathrm{s}^{-1}\right)\end{array}$ & $\mathbf{R}^{2}$ & $\mathbf{k}$ & $\mathbf{n}$ & $\mathbf{a}$ & b \\
\hline \multirow{5}{*}{$\begin{array}{l}\text { Henderson e } \\
\text { Pabis }\end{array}$} & 1,0 & 0,99503 & 0,006799 & - & 1,089382 & - \\
\hline & 1,2 & 0,99483 & 0,006539 & - & 1,066300 & - \\
\hline & 1,4 & 0,99802 & 0,007285 & - & 1,050524 & - \\
\hline & 1,5 & 0,99526 & 0,007109 & - & 1,079087 & - \\
\hline & 2,0 & 0,99647 & 0,007533 & - & 1,060538 & - \\
\hline \multirow{5}{*}{ Midilli et al. } & 1,0 & 0,99983 & 0,001492 & 1,268363 & 1,018884 & $-0,000082$ \\
\hline & 1,2 & 0,99986 & 0,002101 & 1,206379 & 0,999405 & $-0,000064$ \\
\hline & 1,4 & 0,99990 & 0,003042 & 1,144260 & 1,008036 & $-0,000082$ \\
\hline & 1,5 & 0,99984 & 0,003772 & 1,112529 & 1,027158 & $-0,000130$ \\
\hline & 2,0 & 0,99986 & 0,005184 & 1,046921 & 1,027359 & $-0,000200$ \\
\hline \multirow{5}{*}{$\begin{array}{l}\text { Newton e } \\
\text { Lewis }\end{array}$} & 1,0 & 0,99038 & 0,006099 & - & - & - \\
\hline & 1,2 & 0,99058 & 0,005974 & - & - & - \\
\hline & 1,4 & 0,99597 & 0,006787 & - & - & - \\
\hline & 1,5 & 0,99032 & 0,006438 & - & - & - \\
\hline & 2,0 & 0,99356 & 0,006976 & - & - & - \\
\hline \multirow{5}{*}{ Page } & 1,0 & 0,99945 & 0,001353 & 1,299208 & - & - \\
\hline & 1,2 & 0,99972 & 0,001289 & 1,306237 & - & - \\
\hline & 1,4 & 0,99966 & 0,002803 & 1,180716 & - & - \\
\hline & 1,5 & 0,99949 & 0,001605 & 1,280295 & - & - \\
\hline & 2,0 & 0,99904 & 0,002578 & 1,203560 & - & - \\
\hline
\end{tabular}

Conforme a Tabela 2, ambos os modelos analisados apresentaram valores de coeficiente de determinação $\left(\mathrm{R}^{2}\right)$ acima de $99 \%$, o que, segundo Madamba et al. (1996) significa um bom ajuste para a representação do fenômeno de secagem. Quanto aos resíduos, ambos os modelos apresentaram distribuição aleatória, o que é desejável que ocorra.

Analisando os dados da Tabela 2 e as curvas da Figura 3, observa-se que o modelo semi-empírico de Midilli et al. foi o que apresentou os melhores resultados para a secagem da mistura bagaço de malte e levedura, com coeficientes de determinação acima de 99,98\% para 
todas as condições estudadas. Nota-se, também, que o modelo de Page apresentou bastante relevância aos ajustes aplicados nos diferentes fluxos gasosos, obtendo-se um coeficiente de determinação próximo de $99,95 \%$. Este fato se deu pelo modelo empírico representar muito bem a secagem de produtos agrícolas.

Observa-se, também, que ao tratar os dados com o modelo de Midilli houve um incremento no coeficiente de secagem " $k$ ", enquanto o parâmetro " $n$ " decaiu com o aumento das velocidades do ar de secagem. A elevação no coeficiente " $k$ " indica que houve uma maior facilidade na remoção da água com o aumento do fluxo gasoso, já que este parâmetro representa o efeito das condições externas de secagem. A diminuição da constante "n", para as velocidades maiores, é justificada devido à resistência interna do produto a secagem (MISRA, BROOKER, 1980). Observa-se, ainda, que o aumento do fluxo gasoso não alterou significativamente os coeficientes "a" e "b", pois a operação de secagem foi proposta apenas com a temperatura de $70^{\circ} \mathrm{C}$ e estas constantes estão diretamente relacionadas à temperatura do ar de secagem (ADORNO et al., 2013).

Mohamed et al. (2005) ajustaram os dados experimentais da secagem de laranja amarga (Citrus aurantium) ao modelo de Midilli e encontraram valores similares ao do presente trabalho, os autores constataram valores de " $k$ " $e$ " $b$ " inferiores a $1,0(k=0,0218 ; b=-0,0007)$ e dos parâmetros " $a$ " e " $n$ " em torno de $1,0(a=1,0268 ; n=0,9720)$. Desta forma, o tratamento aplicado pelo modelo de Midilli representa adequadamente o fenômeno da secagem da mistura de bagaço de malte e levedura.

Martinazzo et al. (2007) estudaram a cinética de secagem, em camada delgada, de folhas de capim-limão Cymbopogon citratus (D.C.) numa faixa de temperatura de 30 a $60{ }^{\circ} \mathrm{C}$, sendo utilizadas treze equações empíricas e semiteóricas para analisar os dados experimentais de secagem. Os resultados mostraram que o modelo de Midilli foi o que melhor se ajustou aos dados experimentais, apresentando o maior coeficiente de determinação para todos os tratamentos ( 99,70\%) e menor erro médio estimado (oscilação entre 0,0073 e 0,0248).

\section{CONCLUSÃO}

Nas condições em que se realizou o experimento, tem-se que a cinética de secagem da mistura bagaço de malte/levedura está intrinsicamente relacionada à velocidade do fluxo de ar, visto que aumentando-se a velocidade do ar, diminui-se o tempo de secagem, o que reduz, consequentemente, a umidade final do produto.

Nos ajustes dos modelos matemáticos testados, o modelo de Midilli se apresentou com os melhores resultados para a secagem da mistura bagaço de malte e levedura, com coeficiente de determinação acima de 99,98\%, em todas as condições testadas. Entretanto, o modelo matemático de Page também se apresentou como um bom representativo dos dados experimentais, com coeficiente de determinação de aproximadamente 99,95\%.

\section{REFERÊNCIAS}

ADORNO, W. T., MARTINS, G. A. S.; SILVA, W. G. Modelagem matemática aplicada á transferência de massa em alimentos. Enciclopédia Biosfera. Goiânia, v. 9, n. 16, p. 1471, 2013.

ANDRADE, E. T.; BORÉM, F. M.; HARDOIM, P. R. Cinética de secagem do café cereja, bóia e cereja desmucilado, em quatro diferentes tipos de terreiros. Revista Brasileira de Armazenamento - Especial Café, Viçosa, v. 1, n. 7, p. 37-43, 2003. 
AZOUBEL, P. M.; BARBOSA JR., J. L.; MURR, F. E. X. Estudo da cinética de secagem de tomate cereja. Revista Horticultura Brasileira, Campinas, v. 21, n. 2, 2003.

BROCHIER, M. A. Aproveitamento do resíduo úmido de cervejaria na alimentação de cordeiros confinados em fase de terminação. 120 f. Dissertação (Mestrado em Qualidade Ambiental) - Centro Universitário Feevale, Novo Hamburgo, 2007.

BRUCE, D. M. Exposed-layer barley drying, three models fitted to new data up to $150{ }^{\circ} \mathrm{C}$. Journal of Agricultural Engineering Research, v. 32, p. 337-348, 1985.

FOUST, A. S., WENZEL, L. A., CLUMP, C. W.; MAUS, L.; ANDERSEN, L. B. Princípios das Operações Unitárias. ed. 2, Rio de Janeiro: Editora LTC, p. 401-432, 1982.

GOUVEIA, J. P. G. de. Avaliação da cinética de secagem de gengibre (Zingiber officinalle, Roscoe) em um secador de leite fixo. $161 \mathrm{f}$. Tese (Doutorado em Engenharia de Alimentos) - Universidade Estadual de Campinas. Campinas, 1999.

HENDERSON, S. M.; PABIS, S. Grain drying theory I. Temperature effect on drying coefficient. Journal of Agriculture Engineering Research, v. 6, n. 3, p. 169-174, 1961.

JESUS, S. S. de. Desenvolvimento e análise do processo de secagem de $\alpha$-amilase por microondas a vácuo. 173 f. Dissertação (Mestrado em Engenharia Química) - Faculdade de Engenharia Química, Universidade Estadual de Campinas, Campinas, 2002.

MADAMBA, P. S.; DRISCOLL, R. H.; BUCKLE, K. A. Thin-layer drying characteristics of garlic slices. Journal of Food Engineering. v. 29. p. 75-97, 1996.

MARTINAZZO, A. P.; CORRÊA, P. C.; RESENDE, O.; MELO, E. de C. Análise e descrição matemática da cinética de secagem de folhas de capim-limão. Revista Brasileira de Engenharia Agrícola e Ambiental, v. 11, n. 3, p. 301-306, 2007.

MENEZES, M. L. de. Remoção do corante reativo azul $5 G$ a partir de soluções aquosas utilizando o bagaço do maracujá amarelo como adsorvente. 115 f. Dissertação (Mestrado em Engenharia Química) - Universidade Estadual de Maringá. Maringá, 2010.

MIDILLI, A.; KUCUK, H.; VAPAR, Z. A new model for single-layer drying. Drying Technology, v. 20, n. 7, p. 1503-1513, 2002.

MISRA, M. K.; BROOKER, D. B. Thin-layer drying and rewetting equations for shelled yellow corn. Trans. ASAE, St Joseph, v. 23, n. 4, p. 1254-1260, 1980.

MOHAMED, L. A.; KOUHILA, M.; JAMALI, A.; LAHSASN, S.; KECHAOU, N.; MAHROUZ, M. Single layer solar drying behavior of Citrus aurantiun leaves under forced convection. Energy Conversion and Management. Oxford, v. 46, n. 9-10, p. 1473-1483, 2005.

O'CALLAGHAN, J. R.; MENZIES, D. J.; BAILEY, P. H. Digital simulation of agricultural dryer performance. Journal of Agricultural Engineering Research, v. 16, n. 3, p. 223244, 1971.

PINEDO, A. A. Secagem a vácuo de cenoura (Daucus carota) e abobóra (Cucurbita máxima): estudo das características do processo. 195 f. Tese (Doutorado em Engenharia de Alimentos) - Universidade Estadual de Campinas, Campinas, 2003.

\section{AGRADECIMENTOS}

Os autores agradecem a empresa que disponibilizou o resíduo úmido de cervejaria e a UTFPR pelo apoio financeiro dado a esta pesquisa. 